\title{
Demonstration of Heterogeneity in a Natural Population of Rhizobium phaseoli using Variation in Intrinsic Antibiotic Resistance
}

\author{
By J. L. BEYNON* AND D. P. JOSEY \\ John Innes Institute, Colney Lane, Norwich NR4 7UH
}

(Received 6 September 1979)

\begin{abstract}
Two strains of Rhizobium phaseoli, one of which (strain 1234) was resistant to high concentrations of streptomycin, were used to inoculate plots of French beans (Phaseolus vulgaris). Bacteria were isolated from nodules and typed using their intrinsic resistance to low concentrations of seven antibiotics. The inoculum strains were a minority of isolates from inoculated plots. The high concentration streptomycin resistance character was used in the case of strain 1234 to confirm the accuracy of identification. The resident population of $R$. phaseoli was shown to be heterogeneous; 54 different resistance patterns were recorded. Isolates having the same intrinsic resistance pattern, with few exceptions, were uniform in their reaction with antiserum raised against one of the inoculum strains and in their colony morphology.
\end{abstract}

\section{INTRODUCTION}

In field inoculation experiments with Rhizobium it is important to be able to distinguish inoculum strains from any indigenous rhizobia and to recognize the different strains that are responsible for nodulation. Preferably, inoculum strains should be 'wild-type' and the technique used to identify them should be simple and rapid.

Serological techniques have been used extensively for Rhizobium strain identification (Vincent, 1941, 1970; Purchase et al., 1951; Koonty \& Faber, 1961; Škrdleta, 1965). These techniques can be very sensitive (Means et al., 1964; Kishinevsky \& Bar-Joseph, 1978), and have been used to monitor the success of introduced strains (Read, 1953; Dudman \& Brockwell, 1968), and to demonstrate that natural populations of rhizobia may be heterogeneous (Hughes \& Vincent, 1942; Purchase \& Vincent, 1949; Purchase et al., 1951). However, the use of serology is restricted by the limited number of serotypes, the extent of cross-reaction among rhizobia (Graham, 1963a) and by the fact that the preparation of strain-specific antiserum for a large number of strains is an unwieldy process.

The other main identification technique involves high concentration antibiotic resistance markers (Schwinghamer \& Dudman, 1973). This has the advantage of ease of isolation and recognition of inoculum strains from nodules and also from the soil. However, such genetic markers can alter symbiotic abilities compared with the wild-type (Pankhurst, 1977; Jones \& Bromfield, 1978). This technique also gives little information concerning the indigenous population of Rhizobium apart from the percentage of nodules which are not formed by the inoculum strain.

In the laboratory, Pinto et al. (1974) used natural resistance to kanamycin at $2 \mathrm{mg}^{-\mathbf{1}}$ and streptomycin at $1.5 \mathrm{mg} \mathrm{l}^{-1}$ to distinguish strains of $R$. meliloti, and Graham (1963b) showed that strains of several species of Rhizobium had varying resistances to low concentrations of a range of antibiotics. Mahler \& Bezdicek (1978) showed that isolates from a natural population of $R$. leguminosarum exhibited variation in their responses to quite high concentrations of selected antibiotics. 
We have exploited this natural variation in resistance to antibiotics to identify Rhizobium strains (Josey et al., 1979). In this paper we describe the use of this technique to identify inoculum strains of $R$. phaseoli under field conditions and to distinguish a large number of indigenous strains of that species.

\section{METHODS}

Strains. Strains 8115 and 1234 were used for inoculation. The former is a wild-type field isolate; the latter is a spontaneous str (resistant to $200 \mathrm{mg}$ streptomycin $\mathrm{l}^{-1}$ ) mutant of Rothamsted Experimental Station strain 3644. Both these strains had been shown to induce nitrogen-fixing nodules on Phaseolus.

Media. All strains were grown on complete (TY) medium (Beringer, 1974).

Field experiment. A $4 \times 4$ latin square was set up in a commercial crop of dwarf French beans (Phaseolus vulgaris var. Provider) at Hainford, Norfolk (grid reference TG 232174); plots were $5.16 \times 2.88 \mathrm{~m}$ with $1.5 \mathrm{~m}$ gaps between them to minimize the spread of inocula. The trial area was fertilized with phosphate and potash only $\left(100 \mathrm{~kg} \mathrm{ha}^{-1}\right)$ and the four treatments applied were: (1) addition of fertilizer nitrogen (Nitram) at a rate of $197.6 \mathrm{~kg} \mathrm{~N} \mathrm{ha}^{-1}$; (2) uninoculated; (3) inoculated with strain 1234; (4) inoculated with strain 8115. Inoculation was carried out by suspending approximately $10^{10}$ bacteria in 141 water and applying this suspension to each plot with a watering can. (In experiments carried out in soil free from $R$. phaseoli this rate of inoculation gave rise to extensively nodulated plants.) Following this, 35001 water was applied to the whole trial area by overhead irrigation, to ensure that bacteria were washed into the soil and not left to desiccate on the surface.

Isolation of bacteria. Four plants were sampled at random from each plot $67 \mathrm{~d}$ after planting (during pod-filling); nodules were removed and stored in $20 \%(\mathrm{v} / \mathrm{v})$ glycerol at $-17{ }^{\circ} \mathrm{C}$. For each plot, 21 nodules were removed from storage, surface-sterilized by exposure to sodium hypochlorite for 1 min (Beringer, 1974), crushed and, after appropriate dilution, plated on TY agar. A single colony from each nodule was transferred to a small screw-capped vial containing $2 \mathrm{ml} 20 \%$ glycerol; these cultures were then stored at $-17^{\circ} \mathrm{C}$.

Strain identification. (i) Variation in intrinsic resistance to antibiotics: 'fingerprinting'. Each isolate was typed by its intrinsic resistance to low concentrations of antibiotics as described by Josey et al. (1979) using the following antibiotics at the indicated final concentrations (mg $1^{-1}$ ): neomycin sulphate (Neo) 1.25, 2.5; kanamycin sulphate (Kan) 4.0, 10.0; polymyxin B sulphate (Pol) 5.0, 10.0; nalidixic acid (Nal) 5.0, 10.0 (all from Sigma); streptomycin sulphate (Str) 2.5, 10.0 (Glaxo); erythromycin (Ery) 2.5, 5.0 (Cambrian Chemicals); rifampicin (Rif) 1.0, $2 \cdot 0$ ('Rimactane', CIBA). Plates were incubated at $28^{\circ} \mathrm{C}$ for $5 \mathrm{~d}$ before scoring for growth.

Stock cultures of the inoculum strains were included in every set of fingerprinting plates because, as noted by Josey $e$ t al. (1979), a strain's fingerprint can vary with different cultural conditions but accurate strain identification can be obtained by reference to control cultures. Two series of tests were carried out. In the first, the isolates were tested in the order in which they were isolated. In the second, strains with the same or similar phenotypes were grouped and tested together and the two inoculum strains and two field isolates were used as reference cultures on each Petri dish. Field isolates having the same fingerprint were sorted by processing through a PDP11/60 computer.

(ii) Serology. Antiserum was raised against strain 1234 grown on TY slants. The antigen was prepared as described by Vincent (1970) but the bacteria were killed by adding formol-saline $[0.3 \%(\mathrm{v} / \mathrm{v})$ formalin in $0.85 \%(\mathrm{w} / \mathrm{v})$ saline] in the first two of three washes; the final wash and resuspension after centrifugation was in $0.85 \%(\mathrm{w} / \mathrm{v})$ saline. Two rabbits were each injected with approximately $1 \mathrm{ml}$ of bacterial suspension every 2 or $3 \mathrm{~d}$ and both rabbits were bled after $17 \mathrm{~d}$. Injections were intramuscular and subcutaneous. Agglutination tests were carried out in $0.5 \mathrm{ml}$ Dreyer tubes with antiserum from one rabbit at final concentrations of $1 / 100$ and $1 / 800$ and from the other rabbit at $1 / 100$ and $1 / 400$. Agglutination tests were carried out with all the nodule isolates and compared with saline controls. All tubes were incubated overnight at $37^{\circ} \mathrm{C}$ before scoring.

(iii) Other strain identifying characteristics. (a) Resistance to streptomycin at $200 \mathrm{mg}^{-1}$. All isolates were tested for resistance to streptomycin by replica-plating control plates, containing no antibiotics, from the fingerprinting experiment to TY plates containing $200 \mathrm{mg}$ streptomycin $\mathrm{l}^{-1}$.

(b) Colony morphology. The colonies on the control plates from the antibiotic fingerprinting experiment were scored for their morphology after $14 \mathrm{~d}$ (i.e. having been incubated at $28{ }^{\circ} \mathrm{C}$ for $5 \mathrm{~d}$ and then kept at room temperature for a further $9 \mathrm{~d}$ ). Two distinct morphologies were recognized: wrinkled and slimy. 
RESULTS

Plants sampled from all four treatments were nodulated. Mean fresh nodule weight was markedly lower (at the $5 \%$ significance level) in the nitrogen-treated plots $(0.09 \mathrm{~g}$ per plant) than in the uninoculated control $(0.6 \mathrm{~g}$ per plant $)$ or the plots inoculated with strain 1234 $(0.57 \mathrm{~g}$ per plant $)$ or strain $8115(0.50 \mathrm{~g}$ per plant $)$.

Patterns of resistance were established for 259 nodule isolates, 31 of which had unique fingerprints. Twenty-five other fingerprints were recorded which were represented by more than one field isolate. Those fingerprints which occurred more than once are shown in Table 1. Some strains showed variability for resistance to certain antibiotics, e.g. strain 8115 gave both sensitive and resistant results for nalidixic acid at $5 \mathrm{mg} \mathrm{l}^{-1}$ and polymyxin sulphate at $10 \mathrm{mg} \mathrm{l}^{-1}$.

All nodule isolates were tested for their resistance to streptomycin at $200 \mathrm{mg}^{-1}$; only those recognized as strain 1234 by fingerprinting were resistant. In addition to the antibiotic resistance, two other phenotypes were scored, namely, reaction with antisera raised against strain 1234 and colony morphology. Table 2 shows that the great majority of members of a particular group were the same with respect to these two phenotypes, but there were a few exceptions.

The indigenous field isolates forming a particular group were distributed through all four experimental treatments. Only seven isolates were identified as strain 1234 and these all came from plots inoculated with strain 1234. Thirteen isolates were identified as strain 8115 , but five of these were from plots other than those inoculated with strain 8115 . A representative of each of the five major groups (as determined by fingerprinting) was inoculated on to beans and peas under axenic culture conditions (Beringer, 1974); they all nodulated beans but not peas.

\section{DISCUSSION}

The variation in intrinsic resistance of $R$. phaseoli enabled us to identify inoculum strains and to distinguish a range of strains present in an indigenous population. The results presented here demonstrate the validity of this technique.

Strains 1234 and 8115 when re-isolated from nodules could be identified by fingerprinting although they represented only $10 \%$ and $15 \%$, respectively, of the isolates from the plots to which they were inoculated. Isolates identified as strain 8115 from plots not inoculated with this strain could have arisen by inadvertent contamination with strain 8115 or by the presence of an indigenous strain with the same fingerprint.

It appears that there were many strains of $R$. phaseoli present in the small area of the field trial. Fingerprinting showed the indigenous population to be heterogeneous, giving 56 different fingerprints, 25 of which occurred more than once. The technique also showed that one strain was the most common nodule-forming bacterium, i.e. bacteria giving fingerprint 1 (Table 1) were found in a third of the nodules examined. However, this technique does not give an indication of the size of the population of rhizobia in the soil having this fingerprint pattern since it is only testing that proportion of the population which was able to form nodules on the host plant; less competitive or non-nodulating rhizobia are therefore excluded from the sample. Several authors (Hughes \& Vincent, 1942; Purchase, 1948; Purchase et al., 1951) have used serological techniques to analyse natural populations of Rhizobium in nodules; they also found substantial heterogeneity among isolates from the same locality.

The validity of the technique was demonstrated by testing the field isolates for resistance to high concentrations of streptomycin, colony morphology and reaction with antisera raised against strain 1234. When a number of isolates were classified as being in the same group by their antibiotic resistance pattern the great majority of them shared the same 


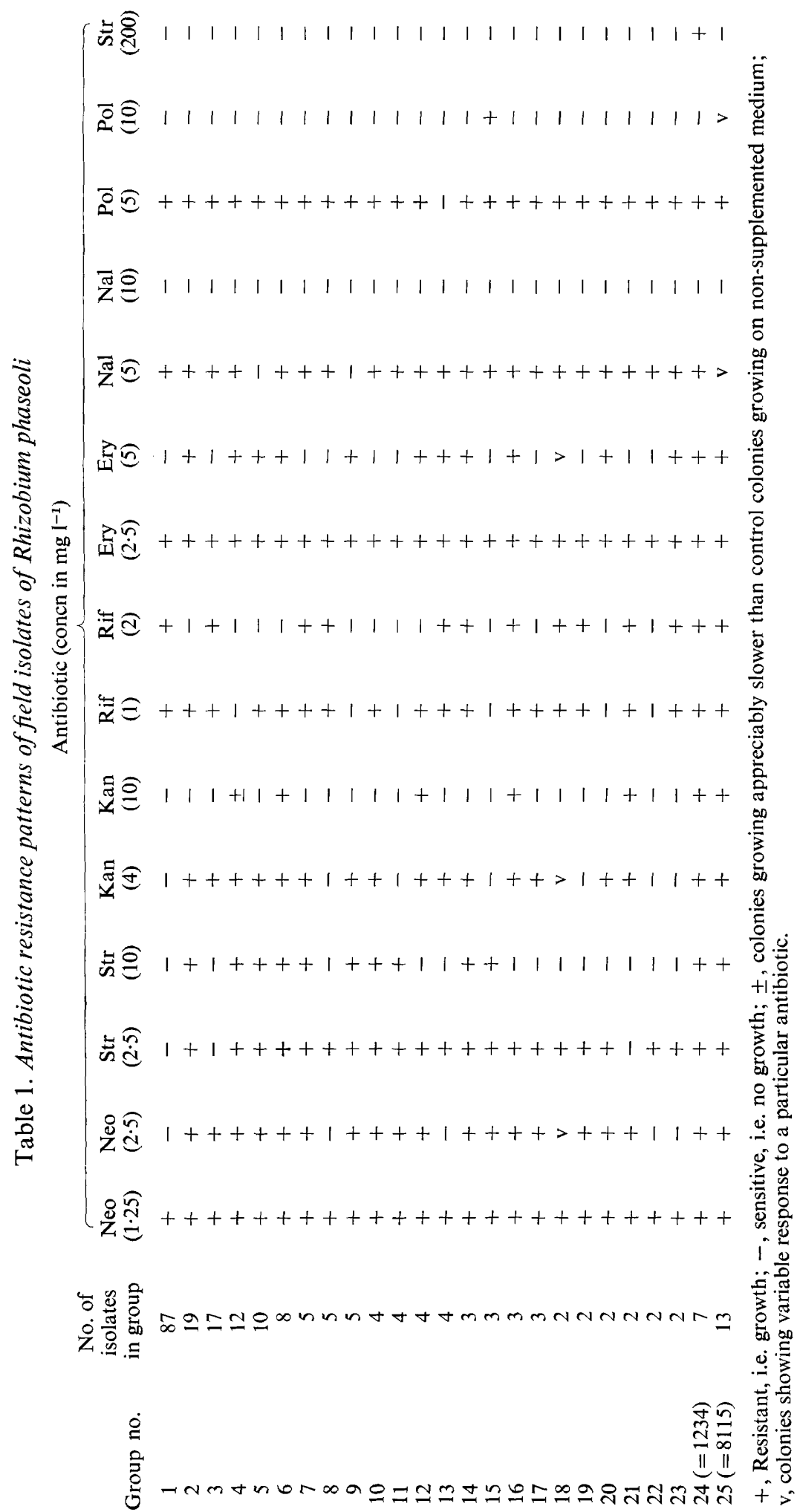


Table 2. Classification of field isolates of Rhizobium phaseoli by colony morphology and antibody response

\begin{tabular}{|c|c|c|c|c|}
\hline \multirow[b]{2}{*}{ Group no. } & \multicolumn{4}{|c|}{ Colony morphology and antibody response* } \\
\hline & $\begin{array}{l}\text { Slimy; } \\
\text { positive }\end{array}$ & $\begin{array}{c}\text { Slimy; } \\
\text { negative }\end{array}$ & $\begin{array}{l}\text { Wrinkled; } \\
\text { positive }\end{array}$ & $\begin{array}{c}\text { Wrinkled; } \\
\text { negative }\end{array}$ \\
\hline 1 & 0 & 0 & 0 & 87 \\
\hline 2 & 4 & 15 & 0 & 0 \\
\hline 3 & 0 & 0 & 17 & 0 \\
\hline $4 \dagger$ & 1 & 10 & 0 & 0 \\
\hline $5 \dagger$ & 0 & 8 & 0 & 0 \\
\hline 6 & 2 & 6 & 0 & 0 \\
\hline 7 & 0 & 0 & 5 & 0 \\
\hline 8 & 0 & 0 & 0 & 5 \\
\hline $9 \dagger$ & 0 & 3 & 0 & 0 \\
\hline 10 & 1 & 3 & 0 & 0 \\
\hline $11 \dagger$ & 0 & 3 & 0 & 0 \\
\hline $12 \dagger$ & 2 & 1 & 0 & 0 \\
\hline 13 & 0 & 0 & 0 & 4 \\
\hline 14 & 3 & 0 & 0 & 0 \\
\hline 15 & 0 & 3 & 0 & 0 \\
\hline 16 & 0 & 2 & 0 & 1 \\
\hline 17 & 3 & 0 & 0 & 0 \\
\hline 18 & 0 & 0 & 0 & 2 \\
\hline 19 & 0 & 1 & 0 & 1 \\
\hline 20 & 0 & 2 & 0 & 0 \\
\hline 21 & 0 & 0 & 2 & 0 \\
\hline 22 & 0 & 0 & 0 & 2 \\
\hline 23 & 0 & 2 & 0 & 0 \\
\hline $24(=1234)$ & 7 & 0 & 0 & 0 \\
\hline $25(=8115)$ & 0 & 0 & 1 & 12 \\
\hline
\end{tabular}

* Slimy and wrinkled refer to colony morphology; positive and negative indicate reaction or lack of reaction, respectively, with antibody raised against whole cells of strain 1234 .

+ Not all strains from these fingerprint groups are included here as some autoagglutination occurred.

characteristics with regard to colony morphology and serotype. All isolates identified as strain 1234 by fingerprinting were also str and no other isolates were resistant to the same high concentration of streptomycin. The fact that the groups could be subdivided on the basis of colony morphology and serotype emphasizes that fingerprinting provided a minimum estimate of the number of strains. This is also indicated by the fact that more than half the fingerprints occurred only once.

Other experiments have shown (unpublished results) that strain 8115 has a variable fingerprint. The results for nalidixic acid at $5 \mathrm{mg} \mathrm{l}^{-1}$ and polymyxin sulphate at $10 \mathrm{mg} \mathrm{l}^{-1}$ are variable and hence the chances of finding natural strains having the same fingerprint in uninoculated plots or those inoculated with strain 8115 are increased. This emphasizes that before using a strain as inoculum it is important to check that it has a stable and distinct fingerprint with the range of antibiotics used. Although the fingerprint of strain 8115 was very similar to that of strain 1234 , the isolates giving this particular resistance pattern could still be distinguished by their colony morphology and response to high concentrations of streptomycin. Thus, other strain characteristics can be used to clarify ambiguities in fingerprinting.

In the UK, nodulation of $P$. vulgaris occurs sporadically (Gane et al., 1975) and since beans had not been grown in the field used for the trial for 5 years, it was surprising to find that the plants were so well nodulated. In addition we have shown, using the fingerprinting technique, that this was not caused by a single strain but by a heterogeneous population of $R$. phaseoli. 
We would like to thank Mr Henley Woods for providing land for the experiment. The Nickerson Seed Co. Ltd and Birds Eye Foods Ltd are gratefully acknowledged for assistance in setting up the trial. We also wish to acknowledge Dr A. W. B. Johnston for continued advice, Dr M. W. Johnson for writing the computer program and Drs J. E. Beringer, N. J. Brewin and Professor D. A. Hopwood for critical reading of the manuscript. D.P.J. was supported by a Research Fellowship funded by a grant from the Ministry of Overseas Development to the John Innes Institute and J. L. B. by an SRC CASE Award in conjunction with the Nickerson Seed Co. Ltd, Rothwell.

\section{REFERENCES}

BERINGer, J. E. (1974). R factor transfer in Rhizobium leguminosarum. Journal of General Microbiology 84, 188-198.

Dudman, W. F. \& Brockwell, J. (1968). Ecological studies of root nodule bacteria introduced into field environments. I. A survey of field performance of clover inoculants by gel immune diffusion serology. Australian Journal of Agricultural Research 19, 739-747.

Gane, A. J., King, J. M., Gent, G. P., Biddle, A. J., Handley, R. P. \& Bingham, R. J. B. (1975). Processors and Growers Research Organisation Pea and Bean Growing Handbook, vol. 1, Beans. Processors and Growers Research Organisation.

Graham, P. H. (1963a). Antigenic affinities of the root-nodule bacteria of legumes. Antonie van Leeuwenhoek 29, 281-291.

GrahaM, P. H. (1963b). Antibiotic sensitivities of the root nodule bacteria. Australian Journal of Biological Sciences 16, 557-559.

Hughes, D. Q. \& Vincent, J. M. (1942). Serological studies of the root-nodule bacteria. III. Tests of neighbouring strains of the same species. Proceedings of the Linnean Society of New South Wales 67, 142-152.

JoNes, D. G. \& Bromfield, E. S. P. (1978). A study of the competitive ability of streptomycin and spectinomycin mutants of Rhizobium trifolii using various marker techniques. Annals of Applied Biology 88, 445-487.

Josey, D. P., Beynon, J. L., Johnston, A. W. B. \& BERINGER, J. E. (1979). Strain identification in Rhizobium using intrinsic antibiotic resistance. Journal of Applied Bacteriology 46, 343-350.

KishineVSKY, B. \& BAR-JoSEPH, M. (1978). Rhizobium strain identification in Arachis hypogaea nodules by enzyme-linked immunosorbent assay (ELISA). Canadian Journal of Microbiology 24, 1537-1543.

Koonty, F. P. \& FABER, J. E. (1961). Somatic antigens of Rhizobium japonicum. Soil Science 91, 228.

MAHLeR, R. L. \& BezdiceK, D. F. (1978). Diversity of Rhizobium leguminosarum in the Palouse of Eastern Washington. Applied and Environmental Microbiology 36, 780-782.

Means, U. M., Johnson, H. W. \& Date, R. A. (1964). Quick serological method of classifying strains of Rhizobium japonicum in nodules. Journal of Bacteriology 87, 547 .

Pankhurst, C. E. (1977). Symbiotic effectiveness of antibiotic resistant mutants of fast- and slowgrowing strains of Rhizobium nodulating Lotus species. Canadian Journal of Microbiology 23, 1026-1033.

Pinto, C. M., Phaik, Y. Y. \& Vincent, J. M. (1974). Nodulating competitiveness amongst strains of Rhizobium meliloti and $R$. trifolii. Australian Journal of Agricultural Research 25, 317-329.

Purchase, H. F. \& Vincent, J. M. (1949). A detailed study of the field distribution of strains of clover nodule bacteria. Proceedings of the Linnean Society of New South Wales 74, 227-236.

Purchase, H. F., Vincent, J. M. \& Ward, L. M. (1951). Serological studies of the root nodule bacteria. Proceedings of the Linnean Society of New South Wales 76, 1.

READ, M. P. (1953). The establishment of serologically identifiable strains of Rhizobium trifolii in field soils in competition with native microflora. Journal of General Microbiology 9, 1-14.

Schwinghamer, E. A. \& Dudman, W. F. (1973). Evaluation of spectinomycin resistance as a marker for ecological studies with Rhizobium spp. Journal of Applied Bacteriology 36, 263-272.

SKroleTA, V. (1965). Somatic sero-groups of Rhizobium japonicum. Plant and Soil 23, 43.

VINCENT, J. M. (1941). Serological studies of the root nodule bacteria. I. Strains of Rhizobium meliloti. Proceedings of the Linnean Society of New South Wales 66, 145-154.

Vincent, J. M. (1970). A Manual for the Practical Study of Root Nodule Bacteria, International Biological Programme Handbook, vol. 15. Oxford: Blackwell Scientific Publications. 